Marcel Bachmann, Michael Rethmeier, Chuan Song Wu

\title{
Sensitivity analysis of the residual stress state in friction stir welding of high strength aluminum alloy
}

Journal article | Accepted manuscript (Postprint)

This version is available at https://doi.org/10.14279/depositonce-10573

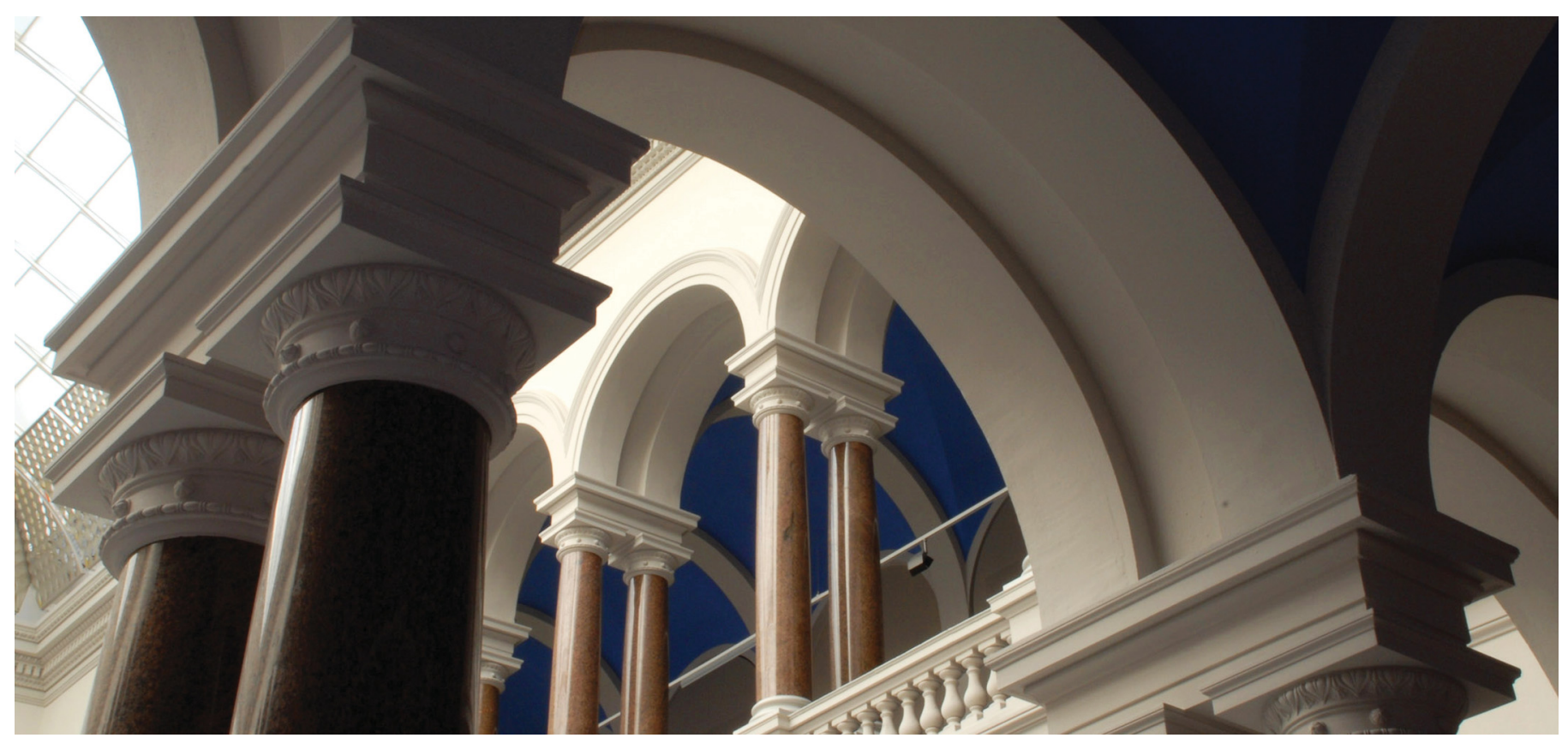

Bachmann, M., Rethmeier, M., \& Wu, C. S. (2016). Sensitivity analysis of the residual stress state in friction stir welding of high strength aluminum alloy. Materials Testing, 58(1), 20-26. https://doi.org/10.3139/120.110809 


\section{Sensitivity analysis of residual stress state in friction stir welding of high strength aluminum alloy}

In this paper, the friction stir welding process was numerically investigated for $6 \mathrm{~mm}$ thick aluminum alloy AA2024-T3. The finite element software COMSOL Multiphysics was used to calculate the transient thermal field during welding and the mechanical reaction depending on different mechanical clamping conditions and hardening models subsequently. A Thermal-Pseudo-Mechanical (TPM) heat source was implemented. Softening effects of the material due to precipitation hardening dissolution caused by the frictional heat were accounted for. The transient temperature evolution measured by thermocouple elements at various locations was compared to the numerical results. A good agreement was found for the thermal field. A sensitivity study of the mechanical models showed the strong influence of the clamping conditions and the softening model.

Keywords: friction stir welding, finite element simulation, residual stress, aluminum alloy, COMSOL Multiphysics

\section{Introduction}

Friction stir welding (FSW) is a modern solid-state joining process invented in 1991 at The Welding Institute (TWI) by Thomas [1]. In this process, a non-consumable rotating welding tool being in contact to the weld specimen by the tool shoulder and the pin, which penetrates the material, creates frictional heat thus plasticizing and softening the material. The weld is created by the movement of the FSW tool along its desired welding path with the applied welding parameters, namely welding speed, rotational speed of the FSW tool and the applied axial force.

The advantages of the FSW process are widespread, e.g. its low temperature being below the melting point thus avoiding solidification cracking phenomena, the high strength of the welded seam, the low energy consumption, low welding distortions, easy weld preparation, no need to use filler material and its high degree of automation $[2,3]$. Thus, materials being known to be hardly weldable with classical joining 
technologies like arc welding or laser beam welding can be fused. The referred advantages make FSW a favorable welding technology in industrial applications, e.g. in the shipbuilding, aerospace, automotive and railway industries [4], especially when regarding sustainability aspects [5] and associated needs to manufacture lightweight structures to lower fuel consumption and save energy. Often, high strength aluminum alloys offer a good compromise between stability and environmental compatibility. Due to their high thermal conductivity, low melting point and high coefficient of thermal expansion, they are difficult to weld with conventional fusion welding technologies. Here, FSW is a preferred process to obtain welds of highest quality without defects.

In FSW, the physical effects of heat generation, material flow and heat flow are strongly coupled as the heat input due to the friction depends on the temperature history and contact conditions between the tool and the workpiece. Therefore, numerical simulations are an essential tool to gain deeper understanding of the FSW process and the underlying physics. Generally, there are two main kinds of simulation in FSW: CFD simulations that can predict the material flow around the rotating tool pin depending on the viscous state of the material in two or three dimensions, e.g. [6-8], and simulations that focus on the structural mechanics, i.e. the residual stresses after welding, e.g. [9-13]. In [14], the influence of the clamping forces on the distortions and residual stresses are investigated thoroughly. The contour method was exploited in [15] to find the M-shaped distribution of longitudinal residual stresses.

CFD as well as mechanical simulations have in common that they need to be based on an accurate thermal simulation, which is often accomplished by analytical heat source models for the sake of convenience [16-18] allowing for a decoupling of the heat transfer simulation from the mechanical part.

Often, simulations in FSW regarding residual stresses in heat-treatable aluminum alloys also incorporate a prediction of the metallurgical state after the welding process. Mainly, they are based on an estimation of the dissolution of hardening precipitates during the thermal cycle [19] without taking into account precipitation nucleation, growth, etc. as well as natural aging effects. 


\section{Numerical approach}

In this paper, the numerical model for the calculation of the residual stresses of an aluminum alloy 2024-T3 in friction stir welding consists of three parts: (a) the calculation of the welding temperature field, (b) the calculation of the softening behavior of the material due to the heat input, and (c) the elastoplastic mechanical simulation, all being solved sequentially with the finite element code COMSOL Multiphysics. A sketch of the process as well as the geometry of the FSW tool is shown in Figure 1. For the simulations, the tilt angle of the tool was assumed to be negligible. The welding speed was set to $60 \mathrm{~mm} / \mathrm{min}$ and the tool rotation to 600 rounds per minute (rpm). The workpiece dimensions are $200 \mathrm{~mm} \times 110 \mathrm{~mm} \times 6 \mathrm{~mm}$.
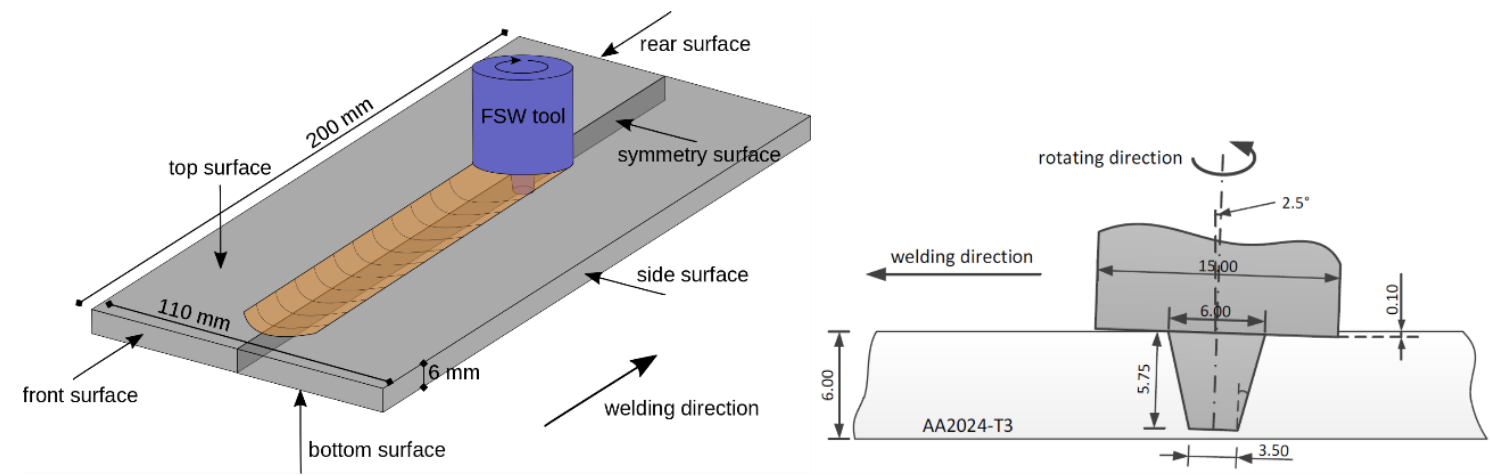

Figure 1: Schematic sketch of the FSW process and the FSW tool used in the experiments

The model exploits half-symmetry, thus the influence of the retreating side (RS) and advancing side (AS) on the temperature evolution in the workpiece during the welding process was not accounted for. The calculation mesh and an exemplary temperature field are shown in Figure 2. The mesh consists of 15200 hexahedral elements. The temperature field and the mechanical simulations used quadratic shape functions, whereas the calculation of the softening was discretized with 4th order elements. 


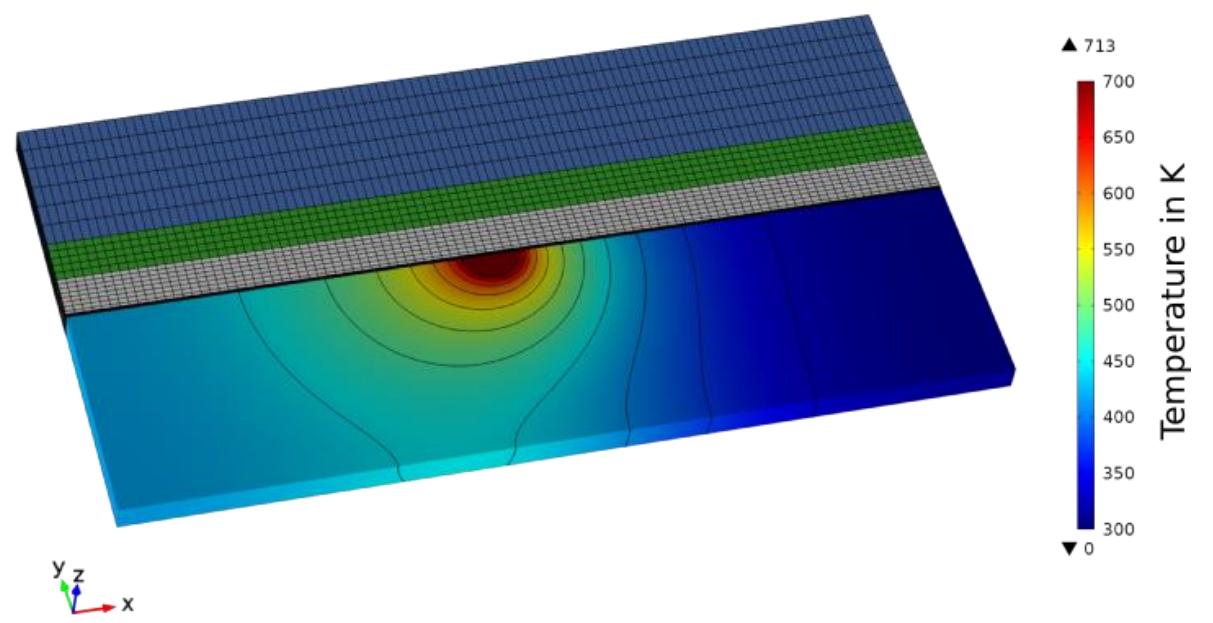

Figure 2: Hexahedral mesh used in the simulations and exemplary temperature distribution at around mid-plate position

The temperature-dependent material properties are shown in Figure 3 and Figure 4. They were taken from [12] as collected from [20, 21].

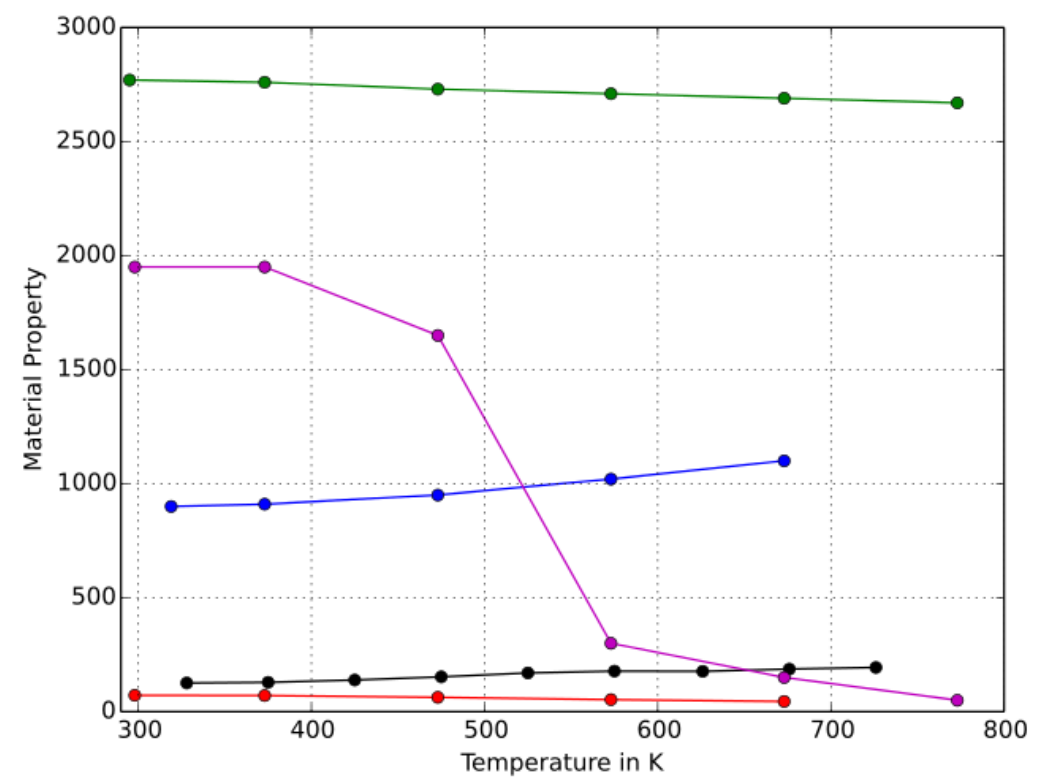

$\bullet$ thermal conductivity in $\mathrm{W} / \mathrm{m} \mathrm{K}$

$\longrightarrow$ density in $\mathrm{kg} / \mathrm{m}^{\wedge} 3$

- heat capacity in J/kg K

- Youngs modulus in GPa

$\longrightarrow$ tangent modulus in MPa

Figure 3: Temperature-depending material properties 

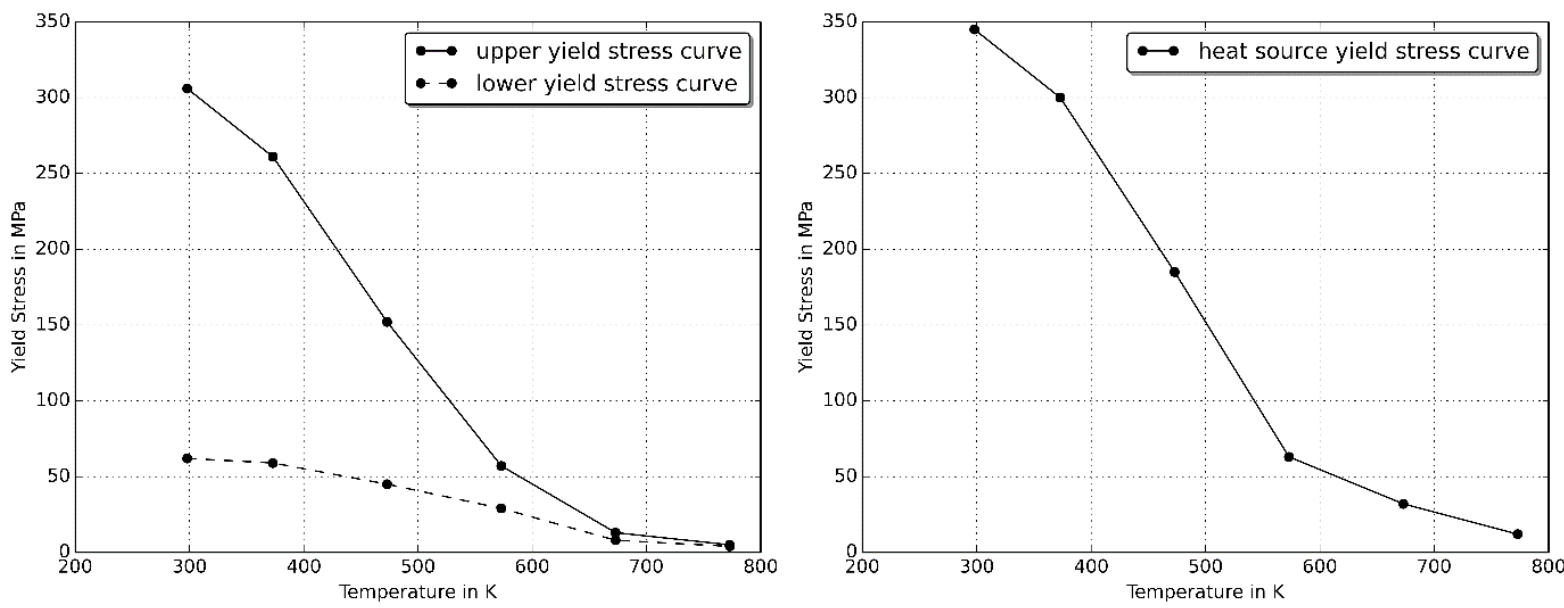

Figure 4: (a) Upper and lower yield stress curves (b) Yield stress curve used for the heat source modelling

Heat transfer. The temperature distribution was calculated according to Equation (1).

$$
\rho c_{p} \frac{\partial T}{\partial t}=\nabla \cdot(k \nabla \mathrm{T})
$$

Here, $\rho, c_{p}, T, t$ and $k$ are the mass density, heat capacity, temperature, time and thermal conductivity, respectively. The heat transfer into the backing plate at the bottom surface during welding was accounted for by a factor 30 increased higher heat transfer coefficient $\left(h=300 \mathrm{~W} / \mathrm{m}^{2} \mathrm{~K}\right)$ compared to the outer air boundaries $\left(h=10 \mathrm{~W} / \mathrm{m}^{2} \mathrm{~K}\right)$. Radiative heat losses were considered using a surface emissivity of 0.25 , see the boundary conditions summarized in Equation (2). $\sigma_{B}$ is the Boltzmann constant.

$$
-\vec{n} \cdot(-k \nabla \mathrm{T})=\left\{\begin{aligned}
0, & \text { symmetry surface } \\
h\left(T_{\text {ext }}-T\right), & \text { bottom surface } \\
h\left(T_{\text {ext }}-T\right)+\varepsilon \sigma_{B}\left(T_{\text {ext }}^{4}-T^{4}\right), & \text { else }
\end{aligned}\right.
$$

The heat input due to the friction at the top surface under the tool shoulder was implemented by the TPM heat source in Equation (3) proposed by [16]), which takes into consideration the tool rotation speed $\omega$, the radial distance under the shoulder $r$ and the temperature-depending yield stress stress $\tau$, which can be expressed in terms of tensile yield stress $\sigma_{\text {yield }}$ (Figure $4(b)$ ).

$$
\frac{\dot{q}}{A}=\omega r \tau(T)=\left(\frac{2 \pi n}{60}\right) r \frac{\sigma_{\text {yield }}}{\sqrt{3}}
$$


The yield stress was taken at $2 \%$ plastic strain and additionally adapted in the hightemperature range (values above $600 \mathrm{~K}$ were doubled compared to the tabulated data in [12]) to ensure a good agreement with the experimental values. The heat input on the top surface due to the tool rotation can be seen in Figure 5. In this plot, positive longitudinal coordinates correspond to the front side of the tool shoulder. The heat input is slightly larger there compared to the rear side due to the local temperature distribution. At the front side, the temperatures are smaller compared to the rear side, thus the shear stresses are higher and more frictional heat can be generated. Heat generation at the tool pin surface as well as by plastic deformation was neglected as it was found to be much smaller than at the tool shoulder [22].

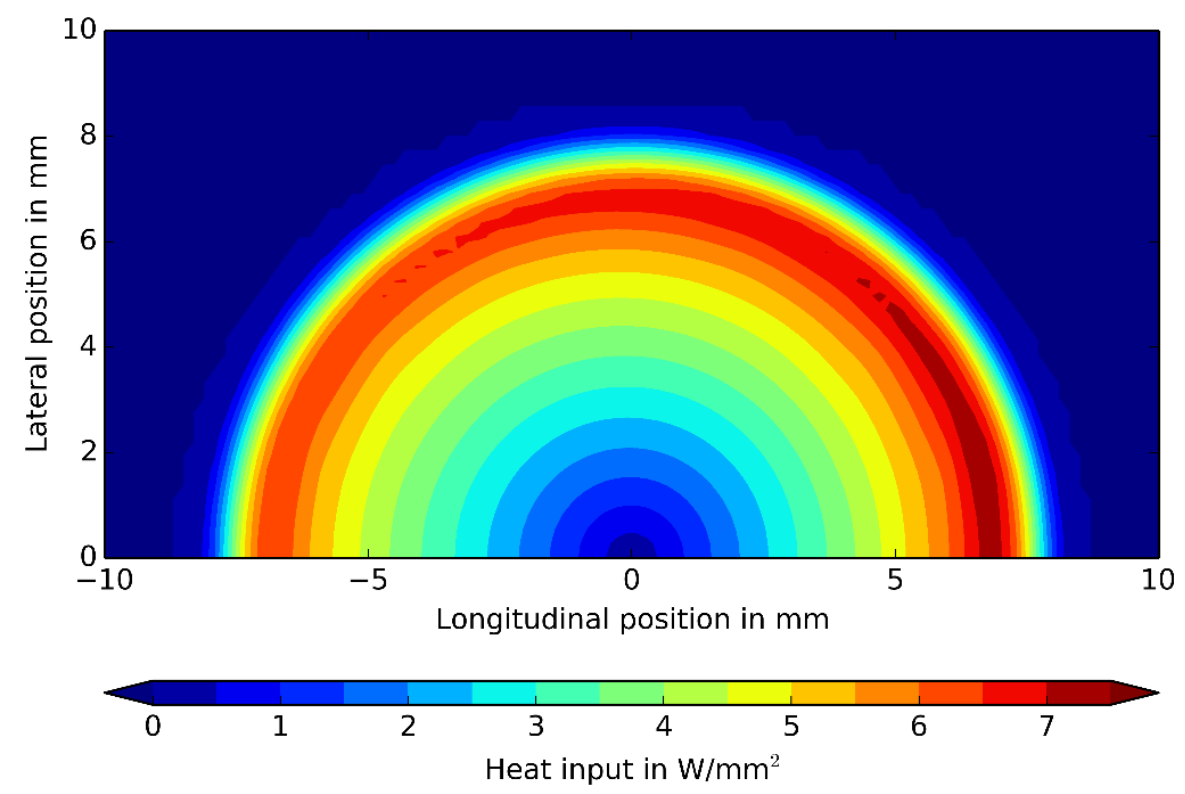

Figure 5: Heat input on the top surface

Softening model. The dissolution of the precipitation hardening due to the heat input was accounted for using the computational model presented in [19]. This effect results in a significant softening of the material and a reduction of the yield strength, consequently. The model relates the fraction of the dissolution of the hardening precipitates $X_{d}$ to an equivalent time of heat treatment $t_{\text {eq }}$. Here, $t_{\text {ref }}$ is the time for a total dissolution at the reference temperature $T_{\text {ref }}, Q_{\text {eff }}$ is the activation energy for the precipitation dissolution and $f / f_{0}$ is the fraction of hardening precipitates. 


$$
\begin{aligned}
& \frac{\partial t_{\mathrm{eq}}}{\partial t}=\frac{1}{t_{\text {ref }} \exp \left\{\frac{Q_{\text {eff }}}{R}\left[\frac{1}{T}-\frac{1}{T_{\text {ref }}}\right]\right\}} \\
& t_{\text {eq }}=\sum_{i=1}^{N} \frac{\Delta t_{i}}{t_{i}^{*}}=\sum_{i=1}^{N} \frac{\Delta t_{i}}{t_{\text {ref }} \exp \left\{\frac{Q_{\text {eff }}}{R}\left[\frac{1}{T_{i}}-\frac{1}{T_{\text {ref }}}\right]\right\}} \\
& \frac{f}{f_{0}}=1-X_{d}=1-\sqrt{t_{\text {eq }}}
\end{aligned}
$$

The resulting yield stress distributions as well as the hardness are depending on the softening grade. The yield stress also depends on the temperature (see Figure 4(b)). Both variables can be calculated by a linear interpolation between the original hard and the fully softened conditions.

$$
\begin{gathered}
H V=H V_{\min }+\frac{f}{f_{0}}\left(H V_{\max }-H V_{\min }\right) \\
\sigma=\sigma_{\min }+\frac{f}{f_{0}}\left(\sigma_{\max }-\sigma_{\min }\right)
\end{gathered}
$$

The parameters of the softening model are summarized in Table 1.

Table 1: Parameters of the softening model taken from [12]

\begin{tabular}{ll}
\hline$T_{\text {ref }}$ & $623 \mathrm{~K}$ \\
$t_{\text {ref }}$ & $16 \mathrm{~s}$ \\
$Q_{\text {eff }}$ & $70.52 \mathrm{~kJ} / \mathrm{mol}$ \\
$H V_{\min }$ & $120 \mathrm{HV} 1$ \\
$H V_{\max }$ & $161 \mathrm{HV} 1$ \\
$\sigma_{\min / \max }$ & see Figure 4 (a) \\
\hline
\end{tabular}

Mechanical model. The residual stresses in the workpiece were calculated by the solution of the transient static force equilibrium with an elastoplastic representation of the mechanic behavior. Hooke's law was adopted with a temperature-depending Young's modulus and a constant Poisson ratio of 0.33. Small plastic strains and a standard von Mises yield criterion were assumed. The coefficient of thermal expansion was taken constant at a value of $2.3210-5 \mathrm{~K}^{-1}$ [9]. An isotropic hardening model was used with a temperature-depending tangent modulus (see Figure 3). For the boundary conditions in the mechanical simulation part, spring foundations acting in normal direction to the applied boundaries were defined for every surface except from the symmetry plane. It was found that numerical convergence could be reached easier in 
this way rather than by a rigid clamping. Two different levels of spring stiffness were investigated referred to as soft and stiff.

\section{Experimental validation}

The experimental welding procedure consists of four stages. The first stage is the tool plunging stage, where the FSW tool enters the workpiece with a plunging speed of $15 \mathrm{~mm} / \mathrm{min}$ and a plunging distance of $5.95 \mathrm{~mm}$. That stage is followed by a first dwelling stage of $15 \mathrm{~s}$ duration to plasticize the surrounding material. In the welding stage, the tool is moved along the welding path with the welding speed. Before pulling out the tool, a second dwelling stage of $2 \mathrm{~s}$ is performed.

The welding speed is $60 \mathrm{~mm} / \mathrm{min}$ with a tool rotation speed of $600 \mathrm{rpm}$. The dimensions of the workpiece as well as the locations of the thermocouples and the residual stress analysis line are shown in Figure 6.

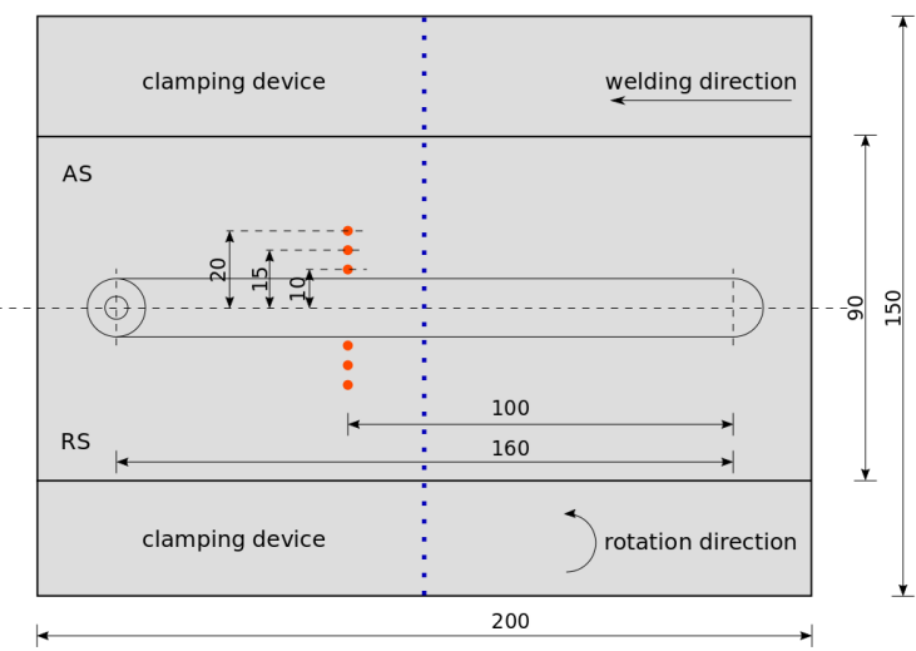

Figure 6: Sketch of the positioning of the thermocouples (orange points) and location for the residual stress analysis (blue dotted line) 


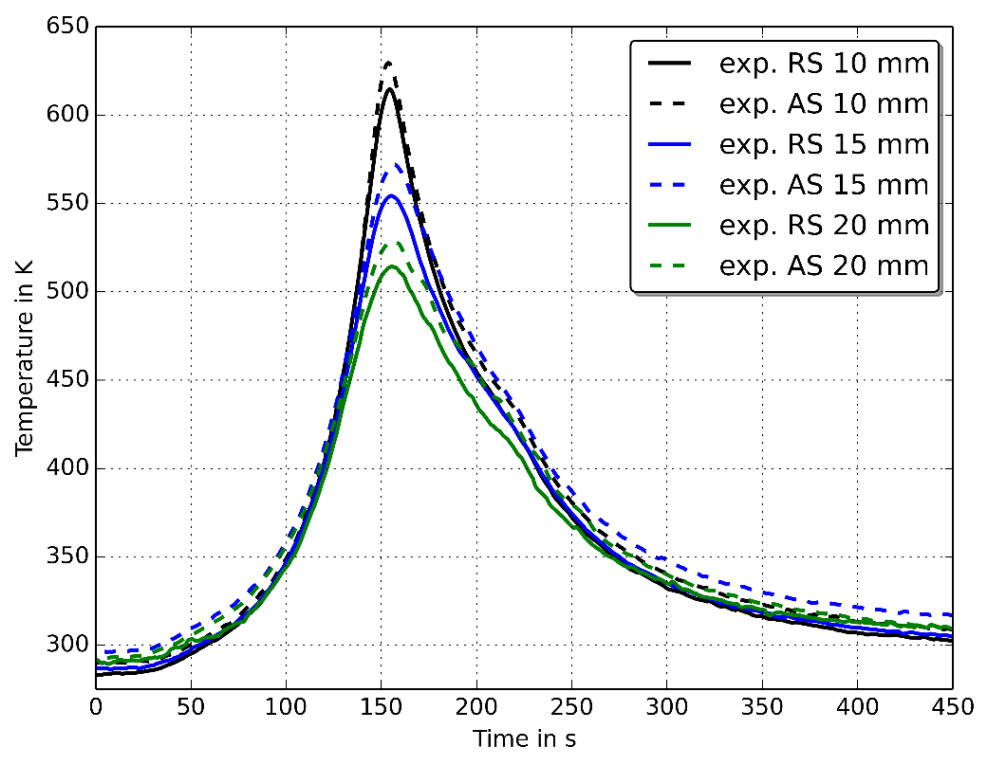

Figure 7: Comparison of experimental temperature time series on the retreating and advancing sides for lateral distances of $10 \mathrm{~mm}, 15 \mathrm{~mm}$ and $20 \mathrm{~mm}$

The recorded time series of the temperature measurements on all six positions on the top surface of the weld specimen can be seen in Figure 7. All measurement positions show a slightly higher temperature on the advancing side which is due to the higher relative speed between the FSW tool and the workpiece compared to the retreating side. The difference in the peak temperature is small enough (see Table 2) to assume half symmetry in the numerical simulations.

Table 2: Peak temperatures during FSW at different lateral positions

\begin{tabular}{rccc}
\hline & $y=10 \mathrm{~mm}$ & $y=15 \mathrm{~mm}$ & $\mathrm{y}=20 \mathrm{~mm}$ \\
\hline $\mathrm{AS}$ & $629 \mathrm{~K}$ & $571 \mathrm{~K}$ & $528 \mathrm{~K}$ \\
$\mathrm{RS}$ & $614 \mathrm{~K}$ & $554 \mathrm{~K}$ & $514 \mathrm{~K}$ \\
\hline difference & $2.4 \%$ & $3.0 \%$ & $2.7 \%$ \\
\hline
\end{tabular}




\section{Results}

Thermal simulation. The comparison between the experimental and the numerical results of the temperature distribution is shown in Figure 8. The experimental values were taken from the retreating sides for all measurement positions.

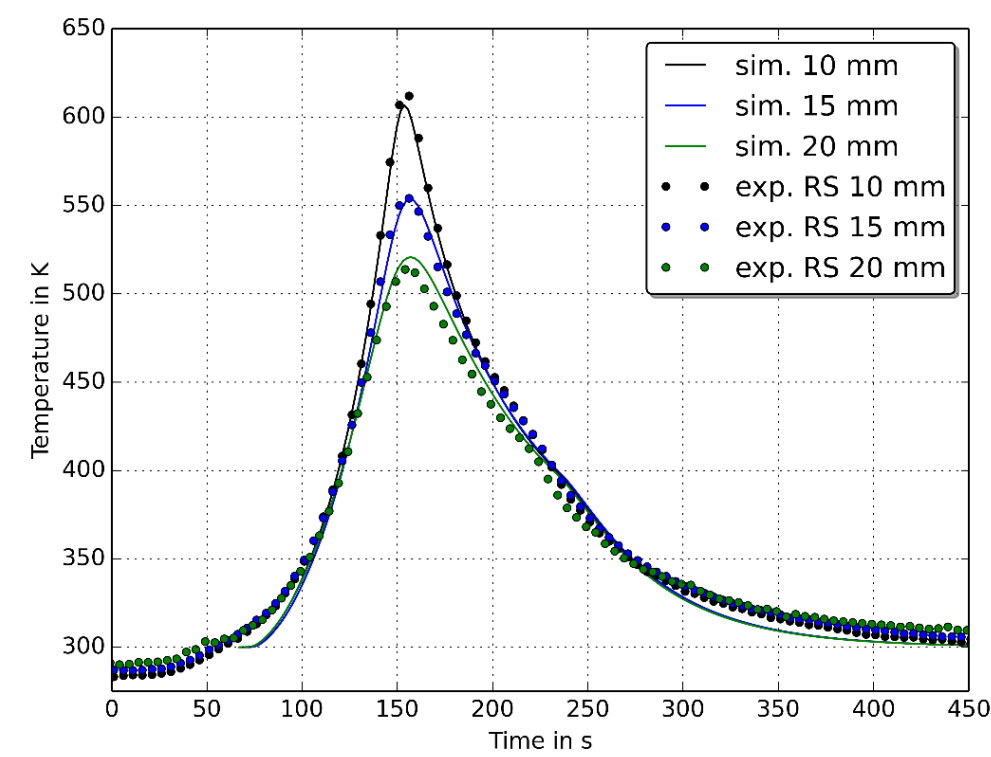

Figure 8: Calculated and experimental temperature time series on the top surface of the workpiece for lateral distances of $10 \mathrm{~mm}, 15 \mathrm{~mm}$ and $20 \mathrm{~mm}$

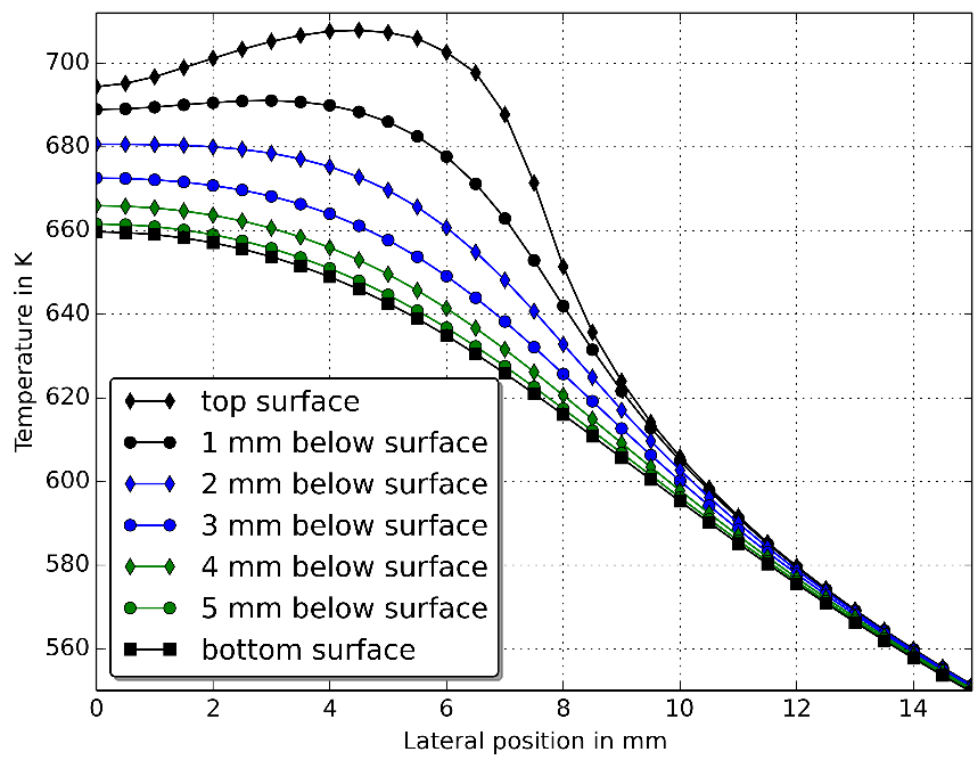

Figure 9: Calculated lateral temperature distributions $(x=100 \mathrm{~mm})$ at different height levels inside the workpiece during heat source passing 


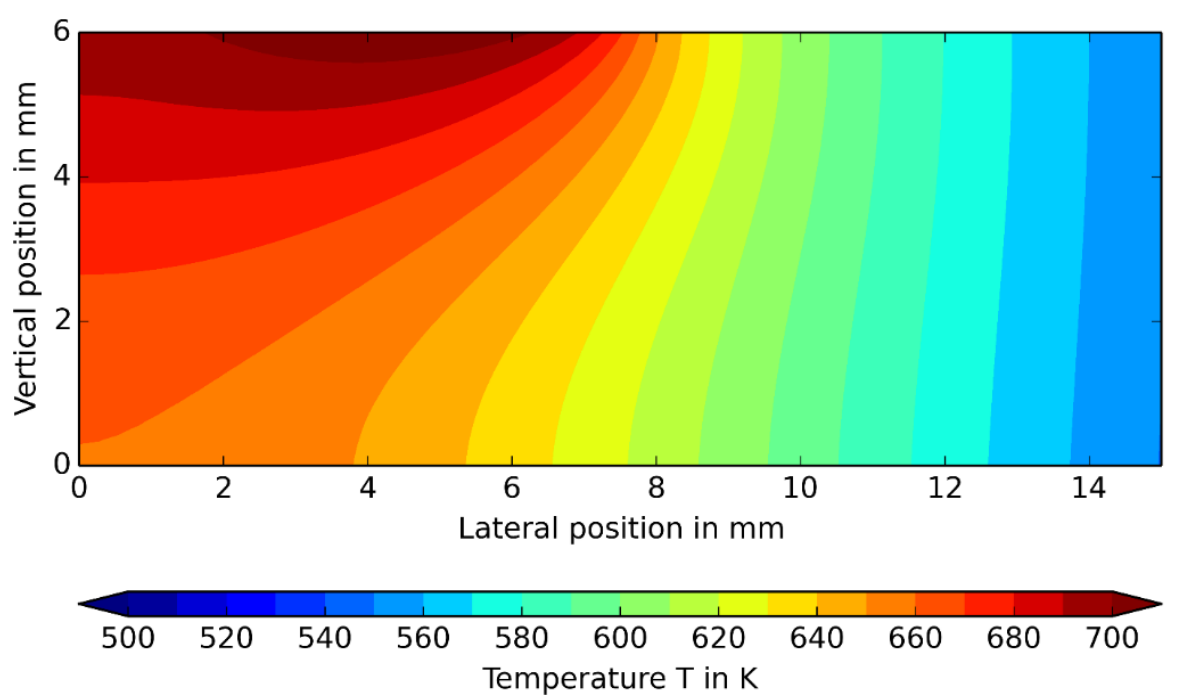

Figure 10: Calculated temperature distribution at the lateral plane at $\mathrm{x}=100 \mathrm{~mm}$ during heat source passing

The FEM results can capture very well the thermal behavior seen in the experiments on the top surface in all three measurement locations, although only the heat generated by the contact between tool shoulder and the workpiece was taken into account in the simulations. Figure 9 shows the temperature distributions at different vertical levels perpendicular to the welding direction. It shows, that the temperature values outside the tool shoulder $(r=7.5 \mathrm{~mm})$ become homogeneously very fast. One can also conclude, that there would be no significant difference in measured temperature values depending on the vertical measurement position, i.e. measuring on the top or the bottom surface or in between, provided that the lateral measuring distance is equal or larger than $10 \mathrm{~mm}$. The same qualitative behavior can be seen from Figure 10, keeping in mind that neither heat input from the tool pin nor volumetric heat generation due to plastic deformation of the material were accounted for. The peak temperatures in the vicinity of the top surface are near the edge of the tool pin as the product of pin radius and yield stress is maximum there. 
Mechanical simulation. The mechanical simulation was performed as a subsequent step after having finished the thermal simulation. The temperature values for each time step served as a thermal load by considering the thermal expansion effect, thus leading to mechanical stresses in the workpiece depending on the material and the mechanical constraints. An exemplary three-dimensional distribution of the temperature field is shown in Figure 11(a). Based on the temperature history and the used softening model, the resulting softening fraction is shown in Figure 11(b). Around the symmetry line, where the heat input due to the tool rotation was maximum, the material was completely softened by the dissolution of the precipitation hardening. Thus, the corresponding yield stress as well as the Vickers hardness distributions not accounting for natural aging effects in Figure 11(c) and Figure 11(d) show a decrease in the vicinity of the weld centerline.

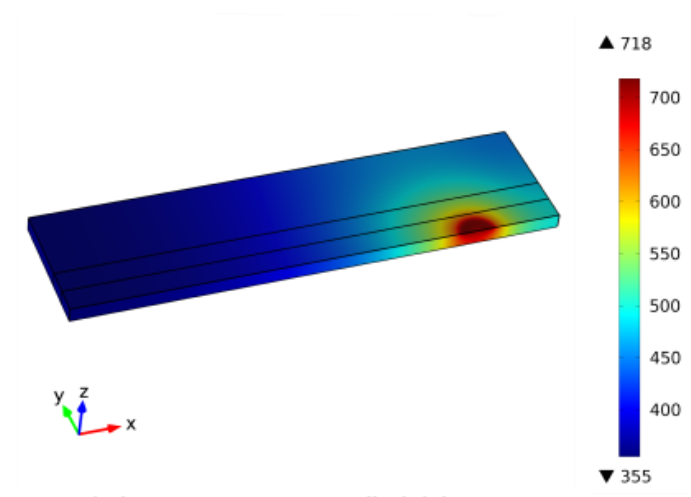

(a) Temperature field in $\mathrm{K}$

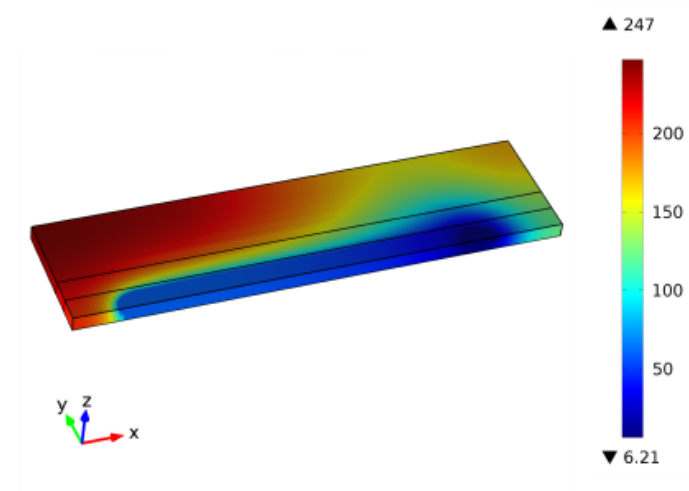

(c) Yield stress in MPa

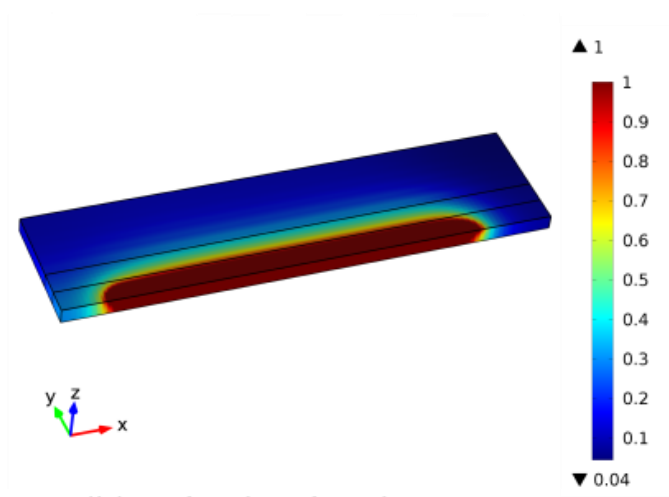

(b) Softening fraction $X_{d}$

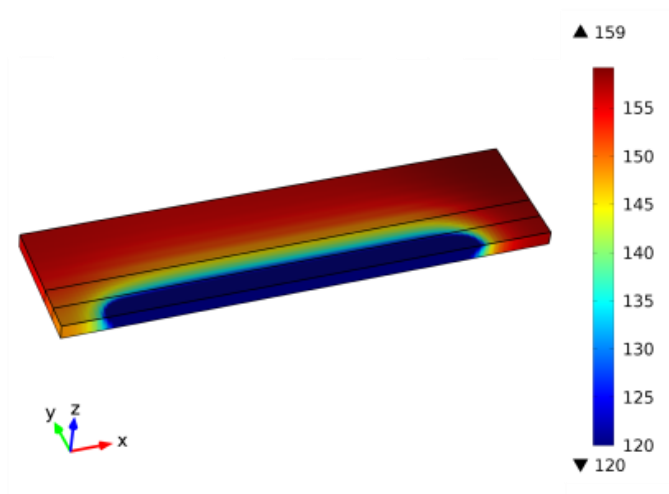

(d) Vickers hardness in HV1

Figure 11: Results of the numerical simulation at the moment just before the FSW tool reaches its final welding position 
Table 3: Sensitivity study overview

\begin{tabular}{|c|c|c|c|c|c|c|}
\hline & \multicolumn{2}{|c|}{ Clamping conditions } & \multicolumn{2}{c|}{ Hardening model } & \multicolumn{2}{c|}{ Thermal softening } \\
\hline & soft & stiff & isotropic & perfectly plastic & yes & no \\
\hline Case 1 & X & & X & & X & \\
Case 2 & X & & X & & X \\
Case 3 & $\mathrm{X}$ & & & $\mathrm{X}$ & $\mathrm{X}$ & \\
\hline Case 4 & & $\mathrm{X}$ & $\mathrm{X}$ & & $\mathrm{X}$ & \\
Case 5 & & $\mathrm{X}$ & $\mathrm{X}$ & & & $\mathrm{X}$ \\
Case 6 & & $\mathrm{X}$ & & $\mathrm{X}$ & $\mathrm{X}$ & \\
\hline
\end{tabular}

In a numerical sensitivity analysis, six different mechanical scenarios were investigated, see Table 3. The used spring coefficient per area for all boundaries except from the symmetry plane was chosen to be $k_{\text {spring }}=10^{9} \mathrm{~N} / \mathrm{m} \mathrm{m}^{2}$ in the soft clamping condition and $k_{\text {spring }}=10^{12} \mathrm{~N} / \mathrm{m} \mathrm{m}^{2}$ in the stiff case. The tangent modulus for the isotropic hardening model is shown in Figure 3. When assuming a perfectly plastic material; the tangent modulus is 0 . The upper yield stress curve in Figure 4(a) was used for the cases without considering the thermal softening effects.

The results of the longitudinal as well as the transversal residual stresses (after unclamping) on the top surface at mid position perpendicular to the welding direction are shown in Figure 12. Evaluating the longitudinal stresses of the soft configuration (cases 1-3), it is evident that the highest values are reached in the configuration without considering the thermal softening effect (case 2). The thermal softening model (case 1) significantly lowers the yield stress in the weld seam (Figure 11(c)) therefore allowing more stress relaxation by plastic deformation and thus lower stress levels. Neglecting the hardening behavior of the material (case 3 ) leads to even smaller stress values in the region of the FSW tool. In the stiff configuration, the observed trends remain the same. In the longitudinal stresses, a clear effect of the thermal softening is visible towards the middle of the weld seam. The stiff configurations (case 5 and 6) show an even more pronounced stress decrement near the centerline of the weld, but even higher stress values away from the tool when compared to the load cases 2 and 3 . The results show that aside from the thermal degradation of the mechanical material properties, also clamping plays an essential role in residual stress development in FSW.

The residual stresses on the top surface in transversal direction show similar trends but on a significantly lower stress level. 

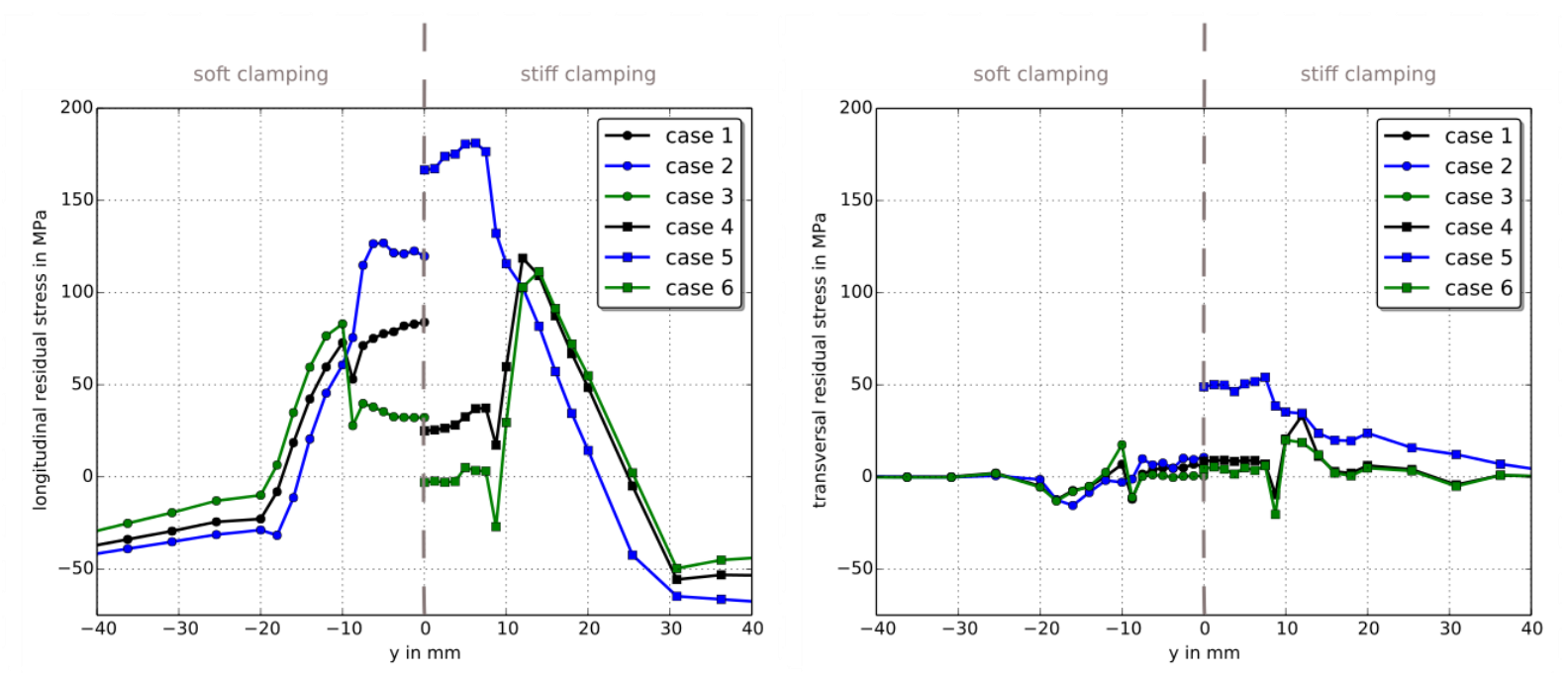

Figure 12: Longitudinal and transversal residual stress results of the welding simulations with a welding speed of $60 \mathrm{~mm} / \mathrm{min}$ and a tool rotation of $600 \mathrm{rpm}$

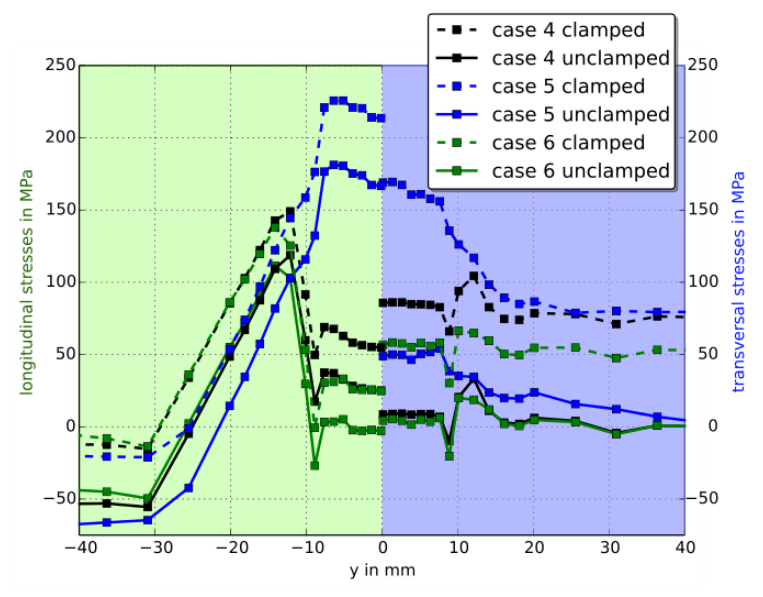

Figure 13: Longitudinal and transversal stresses from the welding simulations with a welding speed of $60 \mathrm{~mm} / \mathrm{min}$ and a tool rotation of $600 \mathrm{rpm}$ for the stiff configuration before and after unclamping 
The influence of unclamping after welding on the stress distributions in longitudinal and transversal directions in the stiff configuration can be seen in Figure 13.

In the longitudinal direction, a subsequent constraint release phase causes a stress decrement of around $25 \mathrm{MPa}$ in the vicinity of the seam when considering the thermal softening (cases 4 and 6). The stress relaxation during unclamping for case 5 without taking into account the dissolution of precipitation hardening is around $50 \mathrm{MPa}$. The transversal mechanical stresses are also lowered by removing the mechanical constraints after welding and cooling down. Here again, the stress decrement of the case without using the thermal softening model reveals the largest stress drop near the FSW tool path.

\section{Summary}

The experimentally measured temperature history of the FSW process could be satisfactory reproduced by the TPM heat source in the simulations. The yield stress in the high temperature range near the melting point was adapted to account for the negligence of the heat generation by the pin and also plastic deformation. It was shown that the differences in the peak temperature for the retreating and the advancing as well as the temperature changes in thickness direction of the plate outside the FSW tool were small.

Two different clamping conditions were investigated. The rigidity of the clamps revealed a distinct influence on the remaining stresses in the workpiece after welding and cooling down being higher for stiffer clamping. A major influence was found due to the used thermal softening model accounting for the dissolution of precipitation hardening leading to a residual stress drop in the plasticized zone. As expected, a subsequent unclamping after the welding process lead to a stress decrease in both longitudinal as well as transversal directions.

\section{Acknowledgements}

The authors are grateful to the financial support for this research from Sino-German Center for the Promotion of Science (Grant No. DFG 739) as well as the Deutsche Forschungsgemeinschaft (Grant No. RE 1648/5-1). 


\section{References}

1. W. M. Thomas, E. D. Nicholas, J. C. Needham, M. G. Murch, P. Temple-Smith, C. J. Dawes: Friction stir butt welding. International Patent Application no. PCT/GB92/02203, December 1991

2. R. S. Mishra, Z. Y. Ma: Friction stir welding and processing, Materials Science and Engineering: R 50 (2005), pp. 1 - 78, doi: 10.1016/j.mser.2005.07.001

3. R. Nandan, T. Debroy, H. K. D. H. Bhadeshia: Recent advances in friction-stir welding-process, weldment structure and properties, Progress in Materials Science 53 (2008), pp. 980 - 1023, doi: 10.1016/j.pmatsci.2008.05.001

4. W. M. Thomas, E. D. Nicholas: Friction stir welding for the transportation industries, Materials \& Design 18 (1997), pp. 269 - 273, doi: 10.1016/S0261-3069(97)00062-9

5. Y. J. Chang, G. Sproesser, S. Neugebauer, K. Wolf, R. Scheumann, A. Pittner, M. Rethmeier, M. Finkbeiner: Environmental and social life cycle assessment of welding technologies, Procedia CIRP 26 (2015), pp. 293-298, doi: 10.1016/j.procir.2014.07.084

6. T. U. Seidel, A. P. Reynolds: Two-dimensional friction stir welding process model based on fluid dynamics, Science and Technology of Welding and Joining 8 (2003), pp. 175 - 183, doi: 10.1179/136217103225010952

7. P. A. Colegrove, H. R. Shercliff: CFD modeling of friction stir welding of thick plate 7449 aluminum alloy, Science and Technology of Welding and Joining 11 (2006), pp. 429 - 441, doi: 10.1179/174329306X107700

8. H. Su, C. S. Wu, M. Bachmann, M. Rethmeier: Numerical modeling for the effect of pin profiles on thermal and material flow characteristics in friction stir welding, Materials \& Design 77 (2015), pp. 114 - 125, doi: 10.1016/j.matdes.2015.04.012

9. M. Z. H. Khandkar, J. A. Khan, A. P. Reynolds, M. A. Sutton: Predicting residual thermal stresses in friction stir welded metals, Journal of Materials Processing Technology 174 (2006), pp. 195 - 203, doi:10.1016/j.jmatprotec.2005.12.013 10. C. M. Chen, R. Kovacevic: Finite element modeling of friction stir welding-thermal and thermomechanical analysis, International Journal of Machine Tools and Manufacture 43 (2003), pp. 1319 - 1326, doi:10.1016/S0890-6955(03)00158-5 
11. J. H. Hattel, M. R. Sonne, C. C. Tutum: Modelling residual stresses in friction stir welding of Al alloys-a review of possibilities and future trends, The International Journal of Advanced Manufacturing Technology 76 (2015), pp. 1793-1805, doi: 10.1007/s00170-014-6394-2

12. M. R. Sonne, C. C. Tutum, J. H. Hattel, A. Simar, B. De Meester: The effect of hardening laws and thermal softening on modeling residual stresses in FSW of aluminum alloy 2024-T3, Journal of Materials Processing Technology 213 (2013), pp. 477 - 486, doi:10.1016/j.jmatprotec.2012.11.001

13. H. T. Serindag, B. G. Kiral, Z. A. Kadayifci: Finite Element Analysis of Friction Stir Welded Aluminum Alloy AA6061-T6 Joints, Materials Testing 56 (2014), pp. 937 - 944 , doi: $10.3139 / 120.110653$

14. V. Richter-Trummer, E. Suzano, M. Beltrão, A. Roos, J. F. dos Santos, P. M. S. T. de Castro: Influence of the FSW clamping force on the final distortion and residual stress field, Materials Science and Engineering: A 538 (2012), pp. 81 - 88, doi:10.1016/j.msea.2012.01.016

15. P. Carlone, G. S. Palazzo: Longitudinal residual stress analysis in AA2024-T3 friction stir welding, Open Mechanical Engineering Journal 7 (2013), pp. 18 - 26

16. H. B. Schmidt, J. H. Hattel: Thermal modelling of friction stir welding, Scripta Materialia 58 (2008), pp. 332 - 337, doi:10.1016/j.scriptamat.2007.10.008

17. M. Song, R. Kovacevic: Thermal modeling of friction stir welding in a moving coordinate system and its validation, International Journal of Machine Tools and Manufacture 43 (2003), pp. 605 - 615, doi:10.1016/S0890-6955(03)00022-1

18. J. Hilgert, H. N. B. Schmidt, J. F. dos Santos, N. Huber: Thermal models for bobbin tool friction stir welding, Journal of Materials Processing Technology 211 (2011), pp. 197 - 204, doi:10.1016/j.jmatprotec.2010.09.006

19. O. R. Myhr, $\varnothing$. Grong: Process modelling applied to 6082-T6 aluminium weldments - I. Reaction kinetics, doi:10.1016/0956-7151(91)90085-F , Il. Applications of model, Acta Metallurgica et Materialia 39 (1991), 2693 - 2708, doi:10.1016/09567151(91)90086-G

20. European Deepweld Project. Detailed multi-physics modelling of friction stir welding. Final Report (2008)

21. J. R. Davis. ASM International: The ASM Specialty Handbook: Aluminium and Aluminium Alloys (1993) 
22. H. Su, C. S. Wu, A. Pittner, M. Rethmeier: Thermal energy generation and distribution in friction stir welding of aluminum alloys, Energy 77 (2014), pp. 720 - 731, doi:10.1016/j.energy.2014.09.045

\section{Biography of the authors}

Dr.-Ing. Marcel Bachmann, born 1984 in Berlin, is with the BAM Federal Institute for Materials Research and Testing in Berlin, Germany in the department "Welding Technology" since 2009. He received his diploma from the Technical University Berlin in Physical Engineering and his Ph.D. for numerical investigations of electromagnetically-assisted high power laser beam welding processes. Currently, he is working on several projects involving numerical simulations in welding processes.

Prof. Dr.-Ing. Michael Rethmeier, born in 1972, is with the BAM Federal Institute for Materials Research and Testing. He is the head of the division "Welding Technology". $\mathrm{He}$ is also heading the "Chair of Safety of Joined Components" at the Institute of Machine Tools and Factory Management, Technical University Berlin. Present research topics include amongst others innovative arc welding processes, high power laser beam welding and numerical simulations in various welding processes.

Prof. Chuan Song Wu, Ph.D, born in 1959, is a professor at the Institute of Materials Joining at the Shandong University in Jinan, China. His research topics include numerical simulation of weld pool shapes in different welding techniques, thermal processes, vision-based intelligent detection and control of welding processes.

\section{Affiliation of the corresponding author}

Dr.-Ing. Marcel Bachmann, BAM Federal Institute for Materials Research and Testing, Unter den Eichen 87, 12205 Berlin, Germany, tel.: +49 308104 3306, fax: +49 308104 1557, email: marcel.bachmann@bam.de 


\section{German summary}

In diesem Artikel wird der Rührreibschweißprozess für $6 \mathrm{~mm}$ dicke Bleche aus AA2024-T3 numerisch untersucht. Die Finite-Elemente-Software COMSOL Multiphysics wurde eingesetzt, um sowohl das transiente Temperaturfeld während des Schweißvorgangs als auch die entstehenden mechanischen Spannungen für verschiedene Einspannbedingungen und Verfestigungsmodelle zu berechnen. Dabei wurde eine Thermo-Pseudo-Mechanische (TPM) Wärmequelle genutzt. Entfestigungseffekte des Materials der durch die Reibwärme bedingten Auflösung der Ausscheidungshärtung wurden berücksichtigt. Die transiente Wärmeausbildung wurde mittels Thermo-Elementen an verschiedenen Positionen gemessen und mit den numerisch ermittelten Werten verglichen. Eine gute Übereinstimmung wurde für das Temperaturfeld erzielt. Eine Sensitivitätsstudie der genutzten mechanischen Modelle zeigt den starken Einfluss der Einspannbedingungen sowie der Entfestigung. 